\title{
Acyclovir ointment plus topical betamethasone or placebo in first episode disciform keratitis
}

\author{
W J Power, M P Hillery, A Benedict-Smith, L M T Collum
}

\begin{abstract}
Thirty patients with first episode disciform keratitis and with no previous steroid exposure were randomly assigned to double blind treatment with $3 \%$ acyclovir ointment and $0 \cdot 1 \%$ betamethasone (Betnesol) drops or acyclovir ointment and matching placebo. In the steroid group 14 of the 15 patients healed in a mean time of 21.8 days. In the placebo group eight of the 13 patients healed in a mean time of 34.5 days. The difference in mean healing time between the two groups was significant $(\mathbf{p}<0.05)$. The cumulative rate of healing was also quicker in the steroid group when compared with the placebo group $(p<0 \cdot 001)$. Other clinical parameters improved more favourably in the combination treatment group. Four patients, two in either group, experienced a mild transient punctate epitheliopathy, but no other serious adverse effects were noted. There has been no significant difference in the recurrence rate between the two groups after a mean follow-up period of approximately 3 years.
\end{abstract}

(Brf Ophthalmol 1992; 76: 711-713)

Acyclovir ophthalmic ointment (3\%) used five times daily has been shown to be effective in the treatment of dendritic and geographic keratitis. ${ }^{12}$ Therapy with acyclovir has been associated with a low incidence of mild transient adverse effects, namely stinging and punctate epitheliopathy. ${ }^{3}$

The aetiology of disciform keratitis is unclear but has been postulated to be viral in origin with an associated delayed type hypersensitivity reaction to herpes antigen within the stroma or endothelium..$^{+6} \mathrm{~A}$ combination of antiviral and steroid would seem to be the optimal therapeutic choice. Acyclovir is a good candidate as it is able to penetrate the intact corneal epithelium and stroma, achieving therapeutic levels in the aqueous humour. ${ }^{7}$ In a previous study we have

Table 1 Patient demography

\begin{tabular}{|c|c|c|}
\hline Parameter & $\begin{array}{l}\text { Acyclovir }+ \\
\text { placebo }(S D)^{\star}\end{array}$ & $\begin{array}{l}\text { Acyclovir }+ \\
\text { betamethasone }(S D)^{\star}\end{array}$ \\
\hline $\begin{array}{l}\text { Age } \\
\text { Corneal thickness } \\
\text { Uveitis: }\end{array}$ & $\begin{array}{l}45(25) \\
1 \cdot 06(0 \cdot 18)\end{array}$ & $\begin{array}{l}53 \cdot 8(24) \\
1.05(0 \cdot 18)\end{array}$ \\
\hline $\begin{array}{l}\text { flare } \\
\text { cells }\end{array}$ & $\begin{array}{l}1.53(0.51) \\
1.13(0.52)\end{array}$ & $\begin{array}{l}1.73(0 \cdot 81) \\
1.4(0.83)\end{array}$ \\
\hline $\begin{array}{l}\text { Duration of symptoms } \\
\text { (days) } \\
\text { Symptoms }(0-3)\end{array}$ & $11 \cdot 7(8 \cdot 0)$ & $10 \cdot 7(9 \cdot 5)$ \\
\hline $\begin{array}{l}\text { pain } \\
\text { photophobia } \\
\text { lacrimation } \\
\text { grittiness }\end{array}$ & $\begin{array}{l}1.20(0.86) \\
2.0(0.98) \\
1.87(0.91) \\
1.20(0.94)\end{array}$ & $\begin{array}{l}1.33(1.0) \\
2 \cdot 33(0.72) \\
2 \cdot 0(0.93) \\
1 \cdot 33(0.98)\end{array}$ \\
\hline
\end{tabular}

*Values given are mean with standard deviation (SD)

All values not significant shown that a combination of acyclovir and dilute steroid was significantly more effective than acyclovir alone in healing herpetic disciform keratitis. ${ }^{8}$ However in that study a significant number of patients had been previously treated with corticosteroids which may have affected the results. The aim of this current study was to compare the efficacy of $3 \%$ acyclovir ophthalmic ointment and $0 \cdot 1 \%$ betamethasone drops (Betnesol) with 3\% acyclovir ointment and placebo for the treatment of first episode disciform keratitis in patients who had no history of previous steroid treatment.

\section{Materials and methods}

Thirty patients with a clinical diagnosis of disciform keratitis were included in the study. Informed consent to participate in the study was obtained from all patients or parents of children, where appropriate. Uniocular patients, patients who had previous ocular surgery, or patients who had received steroid treatment at any time prior to the study were excluded. Diagnosis was based on the history and clinical appearance of the cornea. Details of a history of previous cutaneous herpes or a documented history of previous ocular herpetic ulceration obtained from the patients' notes were recorded. Patients were seen as often as clinically necessary and at all visits a full ocular examination was carried out.

At presentation the area of involved cornea was measured and was scored as follows; $1=0$ $25 \%, 2=25-50 \%, 3=50-75 \%, 4=75-100 \%$. The presence of neovascularisation, either superficial or deep and in how many quadrants, was also recorded. Symptoms of pain, photophobia, lacrimation, and grittiness were scored at each visit on a four point scale $(0=$ absent, $1=$ mild, $2=$ moderate, $3=$ severe). The following parameters were also assessed at each visit; visual acuity, conjunctival injection, epithelial oedema, stromal oedema, folds in Descemet's membrane, endothelial deposits, anterior chamber flare and cells, intraocular pressure, and corneal thickness using a Haag-Streit pachometer. A record was also made of any adverse effects potentially attributable to the treatment.

Patients were randomly assigned to treatment with $3 \%$ acyclovir ophthalmic ointment and either $0.1 \%$ betamethasone drops or placebo in a double blind manner. Treatment was applied to the affected eye five times daily. The eye was not padded. If patients showed deterioration over 5 days or if the condition remained static for 14 days, they were withdrawn from the study. The keratitis was regarded as healed when the corneal thickness had returned to normal, when epithelial and stromal oedema had regressed, 
when endothelial deposits had either disappeared or were old in appearance, and when there was no more activity in the anterior chamber. Patients continued on drops and ointment for 14 days after healing was complete. Over the next 5 weeks the treatment was tapered by reducing the frequency of daily dosage by one each week.

The $t$ test was used to compare treatment groups for age, initial corneal thickness, duration of symptoms, severity of uveitis. The Wilcoxon signed rank test was used to compare initial scores for pain, grittiness, lacrimation, photophobia, and severity of uveitis.

\section{Results}

Fifteen patients were treated with acyclovir and betamethasone and 15 received acyclovir and placebo. The mean age in the steroid group was 53.8 years with a range of 11 to 92 years. The mean age in the placebo group was 45 years with a range of 7 to 77 years. There were 12 males and three females in the steroid group and 11 males and four females in the placebo group. Twenty eight of the 30 patients (14 in each group), had either a history of previous cutaneous herpes or a previously documented dendritic ulcer. One patient in either group did not give a clear history of a previous herpetic infection but the appearance in both was that of a typical herpetic disciform keratitis. A comparison of pretreatment parameters showed no significant differences between the two groups at the $10 \%$ level (two-tailed test). These results are presented in Table 1.

Two patients in either group had superficial corneal neovascularisation limited to one quadrant at presentation. None of the other 28 had evidence of corneal neovascularisation at presentation. The extent of corneal involvement at presentation between the two groups is shown in Table 2. There was no significant difference between the two groups.

Two patients in the placebo group were lost to follow up. Of the remaining 13 patients in this group eight healed in a mean time of 34.5 days, where five were withdrawn from the study. Fourteen of the patients in the steroid group healed in a mean time of 21.8 days and one patient was withdrawn. A comparison of the mean healing time between the two groups showed that the patients in the steroid group healed in a significantly faster time than those in the placebo group $(p<0.05)$. There was also a significantly greater number of withdrawals in the placebo group in comparison with the steroid group, five out of 13 versus one from 15 ( $p=0.035$, Fisher's exact test). One patient in the steroid group was withdrawn as he developed progressive deep corneal neovascularisation encroaching on the visual axis. He was sub-

Table 2 Percentage area of corneal involvement at presentation

\begin{tabular}{lllll}
\hline & $0-25 \%$ & $25-50 \%$ & $50-75 \%$ & $75-100 \%$ \\
\hline $\begin{array}{l}\text { Acyclovir+placebo } \\
\begin{array}{c}\text { (15 patients) } \\
\text { Acyclovir+steroid }\end{array}\end{array}$ & 5 & 7 & 3 & 0 \\
\hline (15 patients) & 4 & 6 & 4 & 1 \\
\hline
\end{tabular}

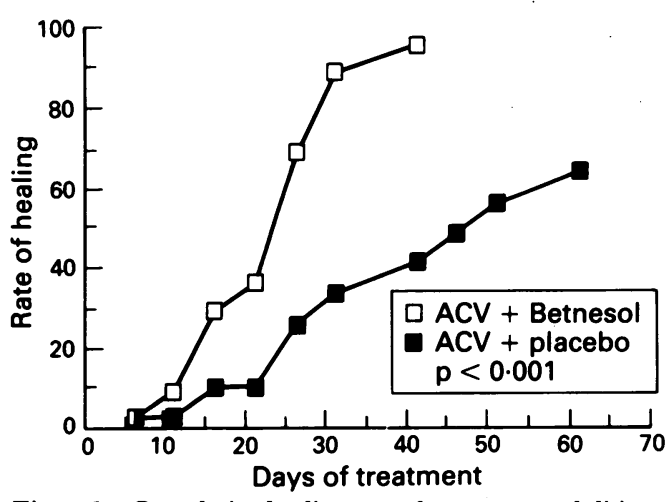

Figure 1 Cumulative healing rate of treatment modalities.

sequently admitted to hospital for treatment and healed in 10 days on acyclovir five times daily and betamethasone four times daily. Five patients in the steroid group were withdrawn; three because of worsening uveitis and two because of the development of progressive deep corneal neovascularisation. The five patients were subsequently treated with acyclovir and dilute steroid. All healed in a mean time of 17 days on this treatment.

The cumulative rate of healing was also examined in both groups and compared using the Mantel Cox test (Fig 1). Patients receiving acyclovir and steroids healed at a significantly faster rate $(\mathrm{p}<0.001)$.

Uveitis and corneal thickness tend to be responsive to steroid treatment. The improvement in these clinical parameters at the end of the study was particularly noticeable in the acyclovir and betamethasone group. From the results presented in Table 3 it can be seen that the patients in the steroid group responded more favourably and virtually all showed improvement. However five patients in the placebo group showed no improvement.

Symptoms of pain, photophobia, lacrimation, and grittiness completely resolved in 14 of the 15 patients receiving acyclovir and betamethasone. In contrast only seven of 13 acyclovir and placebo treated patients had a similar response. However it must be remembered that a large number of this group were withdrawn from the study with active keratitis.

Of the 14 patients who healed in the steroid group, there were seven recurrences (four dendritic ulcers and three cases of disciform keratitis) after a mean follow-up time of 34.5 months. There were three recurrences (two dendritic ulcers and one case of disciform keratitis) in the eight patients who completed the trial in the placebo group after a mean follow-up

Table 3 Progression of corneal thickness and uveitis

\begin{tabular}{llc}
\hline & $\begin{array}{l}\text { Acyclovirt } \\
\text { placebo } \\
(n=13)\end{array}$ & $\begin{array}{l}\text { Acyclovirt } \\
\text { betamethasone } \\
(n=15)\end{array}$ \\
\hline Corneal thickness & & \\
same & 5 & 0 \\
better & 8 & 15 \\
worse & 0 & 0 \\
Uveitis (flare) & 3 & 1 \\
same (cells) & 2 & 1 \\
better (flare) & 10 & 14 \\
(cells) & 11 & 14 \\
worse (flare) & 0 & 0 \\
(cells) & 0 & 0 \\
\hline
\end{tabular}


of 33.4 months. This difference was not significant $(\mathrm{p}=0 \cdot 68)$.

The only adverse event recorded was a mild transient punctate epitheliopathy seen in four patients, two in either group.

\section{Discussion}

The aetiology of disciform keratitis is not fully understood. It is not certain whether it is caused by viral replication within keratocytes and subsequent cell lysis or whether viral antigen entering the corneal stroma alters keratocyte antigenicity and subsequently results in a delayed type hypersensitivity reaction to the herpes antigen within the stroma or endothelium. ${ }^{9}$ This uncertainty in aetiology is reflected in the differing views on treatment of this condition.

McGill, using topical acyclovir alone in patients who had not previously had topical steroids, reported a good response in 14 of 15 such patients in an open label non-placebo controlled trial. ${ }^{10}$ The mean healing time was $44 \cdot 3$ days. However in the present study only eight out of 13 such patients healed on topical acyclovir alone whereas 14 of 15 healed in a shorter time of 21.8 days on the combination therapy. We also found no significant difference in the recurrence rate between the two groups after a follow-up period of nearly 3 years. This is particularly interesting as there have been fears expressed that the use of steroids in the treatment of first episode disci- form keratitis may lead to a higher recurrence rate. ${ }^{10}$

In this study acyclovir combined with $0 \cdot 1 \%$ betamethasone produced a more rapid response with significantly fewer treatment failures than acyclovir and placebo. We therefore conclude that acyclovir without steroids does not provide effective control of first episode disciform keratitis in patients who had not had previous steroid therapy.

1 Collum LMT, Benedict-Smith A, Hiliary IB. Randomised double blind trial of acyclovir and idoxuridine in dendritic corneal ulceration. Br f Ophthalmol 1980; 64: 766-9.

2 Collum LMT, Logan P. McAuliffe-Curtin D, Hung SO, Patterson A, Rees PJ. Randomised double blind trial of acyclovir (Zovirax) and adenine arabinoside in herpes simplex amoeboid corneal ulceration. Brf Ophthalmol 1985; 69: 847-50.

3 Collum LMT, Benedict-Smith A. Acyclovir (Zovirax) in herpes simplex keratitis. In: Herpetische Augener Krankungen, herpes simplex keratitis. In: Herpetische Augener Kra

4 Williams LE, Nesburn AB, Kaufman HE. Experimental induction of disciform keratitis. Arch Ophthalmol 1965; 73: $112-8$.

5 Swyers JS, Lausch RN, Kaufman HE. Corneal hypersensitivity to herpes simplex. Br $\mathcal{F}$ Ophthalmol 1967; 51 : 843-6.

6 Meyers-Elliot RH, Chitiian PA, Dethlefs BA. Experimental herpesvirus keratitis in the rabbit: topical versus intrastromal infection routes. Ophthalmic Res 1983; 15: 240-56.

7 Poirier RH, Kingham JD, de Miranda P, Annel M. Intraocular anti-viral penetration. Arch Ophthalmol 1982; 100: ocular ant

8 Collum LMT, Logan P, Ravenscroft T. Acyclovir (Zovirax) in herpetic disciform keratitis. Br $\mathcal{F}$ Ophthalmol 1983; 67: 1158.

9 Pepose JS. Herpes simplex keratitis: role of viral infection versus immune response. Surv Ophthalmol 1991; 35: 34552.

10 McGill J. The enigma of herpes stromal disease. $\mathrm{Br} f$ Ophthalmol 1987; 71 : 118-25. 